\title{
Gênero, sexualidade e educação: notas para uma "Epistemologia"
}

\section{Gender, sexuality and education: appointments toward an "epistemology"}

\author{
Maria Rita de Assis César*
}

\begin{abstract}
RESUMO
A combinação entre sexualidade e educação é um tema que remonta aos primórdios da instituição escolar brasileira. Muitos projetos e iniciativas de educação sexual pontuaram a história da educação no Brasil e o encontro com a perspectiva de gênero sempre foi problemática. Nos anos de 1990, com o aparecimento dos Parâmetros Curriculares Nacionais, a sexualidade e o gênero passaram a habitar os discursos e as práticas educacionais brasileiros de forma mais bem instalada, mas não menos conflituosa. Este texto analisa os principais caminhos "epistemológicos" que os discursos sobre a sexualidade e o gênero percorreram na instituição escolar ao longo de quase um século. A partir de uma perspectiva ancorada nos conceitos de Michel Foucault, especialmente as noções de dispositivo da sexualidade e biopolítica, analisou-se essa produção discursiva e institucional acerca da sexualidade. Mais contemporaneamente, procurou-se demonstrar as (in) compreensões sobre a diversidade sexual por meio de questionamentos oriundos da teoria queer, tomada como referência decisiva para a discussão da fala docente e de documentos oficiais presentes na escola a respeito de gênero e sexualidade.

Palavras-chave: sexualidade; gênero; práticas escolares; diversidade sexual; teoria queer.
\end{abstract}

* Professora do Departamento de Teoria e Prática de Ensino do Setor de Educ. e do Programa de Pós-Graduação em Educação da UFPR. Pesquisadora do Núcleo de Estudos de Gênero/ UFPR. 


\begin{abstract}
The combination of sexuality and education goes backward to the beginnings of the brazilian educational institution. Many projects and initiatives concerning sexual education have pervaded Brazil's educational history, but facing gender perspectives has always been a troublesome matter. During the 90's, after the appearance of the National Curricular Parameters, both sexuality and gender themes have more frequently inhabited Brazil's educational discourses and practices, although not in a less conflicting manner. The present text discusses the "epistemological" paths that have characterized discourses about sexuality in Brazil's school system throughout the XXth century. Those discursive and institutional productions concerning sexuality were analyzed by means of Foucault's concepts of sexuality dispositive and biopolitics. Contemporaneously, I try to demonstrate some (mis) understandings concerning sexual diversity by means of some concepts from queer theory, which seemed fit to discuss some docent speeches as well as some official documents related to the matter of gender and sexuality in Brazil's schools.
\end{abstract}

Keywords: sexuality; gender; school practices; sexual diversity; queer theory.

\title{
Deslocamentos
}

Gênero e sexualidade na escola, afinal, do que se trata nessa interpelação? Quais os significados das abordagens sobre estes temas no universo escolar? Quais filiações ou traços epistemológicos são utilizados numa abordagem dessa natureza? Por que tratar os temas gênero e sexualidade na instituição escolar? De certa maneira, uma parcela da sociedade brasileira reconhece o lugar estabelecido da sexualidade no interior da escola. Nos últimos vinte anos, após o surgimento da epidemia do HIV/AIDS e o reconhecimento da gravidez de jovens em idade escolar, a sexualidade se consolidou como lugar de fala em torno à ideia de prevenção.

Entretanto, essa história não se iniciou na década de 1990. Na Europa e em suas colônias espalhadas pelo mundo, a preocupação com a sexualidade nas escolas remonta o século XIX, quando a vida regrada dos colégios estabelecera um conjunto de regras sobre o corpo de jovens e crianças. Michel Foucault descreveu os colégios europeus do século XVIII como verdadeiras maquinarias em permanente estado de alerta. Para o autor: "O espaço da sala, a forma das mesas, o 
arranjo dos pátios de recreio, a distribuição dos dormitórios [...], os regulamentos elaborados para a vigilância do recolhimento e do sono, tudo fala da maneira mais prolixa da sexualidade das crianças" (FOUCAULT, 1984, p. 30).

Com efeito, é importante entendermos que uma educação sexual esteve em curso desde os últimos dois séculos, e o próprio Foucault descreveu uma experiência na Alemanha em 1776. Nessa escola experimental, a educação sexual deveria ser tão precisa que "nela o pecado universal da juventude nunca deveria ser praticado" (FOUCAULT, 1984, p. 31). O autor narra uma festa escolar:

\begin{abstract}
Aí ocorreu a primeira comunhão solene do sexo adolescente com o discurso racional, sob a forma mesclada de exame, de jogos florais, de distribuição de prêmios e de conselho disciplinar. [...] Diante do público reunido, um dos professores, Wolke, formulou aos alunos questões selecionadas sobre os mistérios do sexo, do nascimento, da procriação: levou-os a comentar gravuras que representavam uma mulher grávida, um casal, um berço. As respostas foram esclarecidas, sem embaraço nem vergonha. Nenhum riso indecoroso veio perturbá-las - salvo, justamente, da parte de um público adulto bem mais infantil do que as próprias crianças e ao qual Wolke repreendeu severamente. Finalmente, foram aplaudidos os meninos rechonchudos que, diante da gente grande, traçaram com destro saber as guirlandas do discurso e do sexo (FOUCAULT, 1984, p. 31).
\end{abstract}

Com essa narração, Foucault indicou o estabelecimento de um importante elemento por ele analisado, isto é, a colocação do sexo em discurso. Esta insistência discursiva constituiu, ao contrário daquilo que se acostumou a pensar sobre o silenciamento em torno do sexo e das práticas sexuais, a produção de um discurso verdadeiro sobre o sexo que, por sua vez, não poderia se calar. Tratava-se de falar sem corar-se, de falar racionalmente sobre o sexo, de utilizar um saber recém produzido pelo discurso e pelas práticas institucionais da medicina e da psiquiatria, ou seja, tratava-se de falar a verdade do sexo.

As primeiras preocupações explícitas em relação à educação do sexo de crianças e jovens no Brasil tiveram lugar nos anos vinte e trinta do século XX. Nesse momento a educação sexual já era uma preocupação para médicos, intelectuais, professores e professoras que então povoavam o universo educacional brasileiro. No ano de 1922, o importante intelectual e reformador educacional brasileiro, Fernando de Azevedo, respondeu a um inquérito promovido pelo Instituto de Higiene da Faculdade de Medicina e Cirurgia de São Paulo sobre educação sexual. Por aquela ocasião o intelectual destacava a importância do ensino da matéria para o "interesse moral e higiênico do indivíduo" e para o 
"interesse da raça" (MARQUES, 1994). Assim nascia o interesse da educação nacional pela educação sexual como objeto de ensino nas escolas brasileiras.

Em 1933 foi fundado na cidade do Rio de Janeiro, então capital federal, o Círculo Brasileiro de Educação Sexual, que editou um periódico denominado Boletim desde o ano da sua criação (1933) até 1939 (SOUZA, 2002). Ao contrário das ideias que se estabeleceram no imaginário a respeito da ocultação sobre o sexo e as práticas sexuais, desde o final do século XVIII e, especialmente, desde o século XIX, o sexo já era objeto de discussões entre médicos e educadores que defendiam a presença de uma educação para a higiene sexual dos jovens (CÉSAR, 2008). Estas primeiras tentativas do século XX em defesa da educação sexual nas escolas brasileiras se dava por meio de pressupostos higienistas e eugênicos.

A partir de perspectivas bem estabelecidas, a fala da sexualidade e não o seu silêncio constituiu-se como fator importante no discurso educacional brasileiro. Se relacionarmos o processo de escolarização à disciplinarização dos corpos de crianças e jovens, veremos que a educação do sexo encontrou seu lugar privilegiado na escola desde muito cedo. Assim, o "sexo bem educado" se apresentou como parte fundamental do processo de escolarização, mesmo que este não tenha sido abordado sob a rubrica de uma disciplina específica, pois a regulação do sexo de crianças e jovens nas escolas foi uma tônica na conformação da pedagogia moderna (COSTA, 1983). Certamente, a instituição escolar se transformou ao longo do século XX. Ora conservadora, ora revolucionária, ora progressista, ora liberal. A partir dos anos de 1960, os movimentos pelos direitos civis, as lutas feministas, os movimentos gays e lésbicos, as reivindicações étnico-raciais e, na América Latina, as lutas contra os regimes ditatoriais, produziram marcas no discurso sobre na escola.

Um segundo momento importante em relação à produção discursiva e as práticas pedagógicas da educação sexual no Brasil deu-se nos primeiros anos da década de 1960. Pouco antes da ditadura militar, o Brasil vivia um clima de "renovação pedagógica", as críticas sociológicas sobre os sistemas educacionais começavam a ser formuladas e aplicadas em escolas experimentais ${ }^{1}$. Foi justamente nesse período que o tema da educação sexual retornou de forma mais sistemática ao discurso pedagógico. Nessa que podemos chamar de segunda onda da educação sexual brasileira, escolas de São Paulo, Rio de Janeiro e Belo Horizonte organizaram programas de educação sexual em conexão com

1 Estes movimentos de renovação constituem as primeiras ressonâncias daquilo que será uma crítica educacional formulada em vários continentes. No Brasil, Paulo Freire será o nome principal. Entre os europeus destacam-se Louis Althusser, Pierre Bourdieu, Jean-Claude Passeron, Basil Bernstein e Michel Young. Mencionem-se ainda os economistas norte-americanos Samuel Bowles e Herbert Gints e o canadense Willian Pinar em 1973 (SILVA, 1999). 
as "novidades pedagógicas" e curriculares de então. Nas escolas paulistas destacaram-se as experiências desenvolvidas tanto na Escola de Aplicação da Universidade de São Paulo quanto no Colégio Vocacional e nos Colégios Pluricurriculares. Estas experiências específicas de educação sexual e todas as demais experiências pedagógicas originadas dessas instituições foram reprimidas e suprimidas pela ditadura militar.

No início da ditadura militar, em 1965, uma portaria do secretário de Estado dos Negócios da Educação do Estado de São Paulo proibiu professores do ensino secundário, em especial os de Biologia e de Sociologia, de exporem nas escolas sobre a sexualidade e sobre a contracepção (WEREBE, 1998, p. 174). Entretanto, naquele período, o interesse crescente pela educação sexual entre as/ os educadoras/es brasileiras/os levou a deputada federal Júlia Steimbruck, em 1968, a apresentar um projeto de lei propondo a introdução da educação sexual obrigatória nas escolas primárias e secundárias do país (WEREBE, 1998, p. 173). Como a ditadura impôs um regime de controle e moralização dos costumes, especialmente decorrente da aliança entre os militares e o majoritário grupo conservador da igreja católica, a educação sexual foi definitivamente banida de qualquer discussão pedagógica por parte do Estado e toda e qualquer iniciativa escolar foi suprimida com rigor. As iniciativas que conseguiam resistir e burlar o controle se tornaram experiências de resistência e, nas décadas seguintes, a educação sexual foi tomada como um dos marcos educacionais das lutas pela democratização do país. No período ditatorial, portanto, a educação sexual e os debates sobre gênero ou feminismo apareceram como parte de um projeto de escola e educação que se instaurou nas bases das lutas pela redemocratização do país, e nesse momento a educação sexual apareceu como uma reivindicação importante do movimento feminista brasileiro ${ }^{2}$. Naquele momento, a escola foi tomada como o lugar privilegiado dos processos de redemocratização e a educação sexual como uma proposta libertadora dos corpos, das mulheres e sujeitos.

Entretanto, a ligação entre a educação sexual e o movimento feminista produziu apenas marcas leves nas práticas pedagógicas de educação sexual no Brasil, as quais logo desapareceram. Essa vinculação da educação sexual com as questões que cercavam a luta contra o patriarcado e a hierarquia de gênero foi abandonada e o feminismo como campo de indagação das práticas pedagógicas desapareceu sem deixar rastros. Com efeito, na mesma medida em que o

2 Entre as décadas de 1970 e 1980, nas lutas contra a ditadura e no decorrer do processo de redemocratização, as experiências e projetos de educação sexual estiveram fortemente ligados a intelectuais feministas como Carmem Barroso e Cristina Brusquini (BARROSO, 1980, 1982; BRUSQUINI; BARROSO, 1983). 
feminismo desapareceu como "epistemologia" das práticas pedagógicas sobre a sexualidade, a educação sexual começou a se fortalecer como campo específico da saúde. Assim, no início dos anos 80, o discurso da saúde e da biologia ocupara por completo esse espaço "epistemológico". Em uma pesquisa realizada em fontes documentais da secretaria municipal de educação do município de Curitiba-PR, a educação sexual já é pensada nos anos de 1970 tendo em vista a prevenção de doenças sexualmente transmissíveis e curiosidades sobre a reprodução e fisiologia humana, incluída nos procedimentos pedagógicos sobre o planejamento familiar ${ }^{3}$.

Duas décadas mais tarde, a epidemia de HIV/AIDS terá um grande impacto na educação, na medida em que crescia o paradigma da informação como "arma" contra a epidemia. Assim, a escola no início dos anos 90 foi tomada como um lugar fundamental para a propagação de informações sobre o "sexo seguro", as quais incluíam, além do contágio do HIV/AIDS e outras DSTs, a "gravidez na adolescência", que para os especialistas começou a ser tomada como um "problema pedagógico" importante. A partir desse momento, o discurso da sexualidade nas escolas brasileiras foi definitivamente colonizado pela ideia de saúde e prevenção de doenças sexualmente transmissíveis e da gravidez na adolescência, tomadas como sinônimo de problema de saúde física e social. O tema da prevenção foi assumido de maneira tão definitiva que os programas estabeleceram uma conexão direta com outro problema que deveria ser debelado no interior da instituição escolar, isto é, o uso de drogas. Assim, projetos como prevenção de DST/AIDS, gravidez e uso de drogas foram desenvolvidos com base na ideia de prevenção como paradigma do discurso sobre a educação sexual.

Na segunda metade dos anos de 1990, no âmbito de um conjunto de reformas educacionais, o governo brasileiro produziu um importante documento - os Parâmetros Curriculares Nacionais. Os PCNs foram concebidos como resposta e solução para grande parte dos problemas educacionais no Brasil, bem como resposta à inserção na Constituição de 1988 de temas oriundos dos movimentos sociais, tais como as questões étnico-raciais, o meio-ambiente, a educação sexual e as questões de gênero, esquecidas desde os projetos dos anos 70 (CÉSAR, 2004). Inspirada pela reforma educacional espanhola organizada pelo partido popular, ultraconservador, no início dos anos 90, a educação brasileira tomou para si a concepção dos temas transversais e instituiu a educação sexual como um dos temas a serem trabalhados nos PCNs. O fascículo sobre o Tema Transversal Orientação Sexual, publicado em 1997, consolidou definitivamente a escolarização de uma educação do sexo.

3 Trata-se de pesquisa em andamento no meu grupo de pesquisa, realizada por Santina Célia Bordini. 


\section{A invenção da sexualidade e seus desdobramentos}

O filósofo francês Michel Foucault (1984) produziu uma obra em três volumes intitulada História da Sexualidade, entre 1976 e 1984. Em 1976 publicou o primeiro volume, que recebeu o subtítulo de $A$ vontade de saber (FOUCAULT, 1984). Nessa obra Foucault tomou a sexualidade como uma criação discursivo-institucional, cuja função seria o controle dos indivíduos e das populações. Para Foucault:

A sexualidade é o nome que se pode dar a um dispositivo histórico: não à realidade subterrânea que se aprende com dificuldade, mas à grande rede de superfície em que a estimulação dos corpos, a intensificação dos prazeres, a incitação ao discurso, a formação dos conhecimentos, o reforço dos controles e das resistências, encadeiam-se uns aos outros, segundo algumas grandes estratégias de saber e poder (FOUCAULT, 1984).

O autor demonstrou que o sexo e as práticas sexuais se comportavam como parte do chamado dispositivo da sexualidade, pois aquilo que estava em jogo seria essencialmente uma rede estabelecida de saber-poder atuando sobre os corpos e populações ao produzir normatizações e modos de vida. Assim, o sexo foi delimitado como um ponto de injunção fundamental entre o corpo e as práticas de controle das populações no século XIX. Neste processo de estabelecimento de fronteiras, a sexualidade foi o instrumento de separação que criou delimitações entre práticas sexuais bem educadas e as demais, que ocupariam lugar indefinido ou bem demarcado para além das fronteiras da normalização. O sexo bem educado ou normatizado, isto é, as práticas heterossexuais, monogâmicas, consolidadas pelo matrimônio e reprodutivas, foram observadas pelos olhares e ouvidos atentos de médicos e psiquiatras, que podiam até mesmo prescrever mais sexo e a intensificação do prazer. As práticas outras, ou as sexualidades não normativas, deveriam ocupar o lugar das margens, além de serem também esquadrinhadas por médicos e terapeutas que produziram saberes que definiram as configurações e nomenclaturas desses outros da sexualidade - o homossexual, a histérica, o onanista e o casal malthusiano, como bem definiu Foucault. O conceito de sexualidade que pertence a nossa história nasceu como a justa medida de separação entre normalidade e anormalidade (FOUCAULT, 1984).

Não se pode dizer que os efeitos do dispositivo da sexualidade tenham desaparecido por completo, três décadas após sua descrição e análise. Todavia, 
observamos alguns deslocamentos, pois já não nos preocupamos mais com a masturbação das crianças, por exemplo. Nesse meio tempo, entretanto, talvez tenhamos criado outros mecanismos tão perversos quanto os anteriores, na medida em que, por exemplo, ainda nos deparamos com uma verdadeira obsessão médica com o corpo, com a saúde e, sobretudo, com as chamadas "identidades sexuais". Assim, é possível que nossa história da sexualidade tenha uma origem e desdobramentos com os quais não desejamos mais ter qualquer familiaridade, mas certos desdobramentos dessa história são ainda exemplos de exclusão e violência em torno das práticas sexuais não normativas. Talvez ainda venhamos a perceber que, paradoxalmente, a educação sexual no contexto escolar contemporâneo possa ser um espaço para entendermos a história da sexualidade do ponto de vista dos nossos mecanismos de exclusão e de produção da norma sexual, de modo que possamos resistir aos mecanismos de produção e reprodução da norma. Se isso acontecer, a educação sexual nas escolas será, antes de tudo, um ato político.

Quase um século depois das primeiras tentativas de organizar um programa de educação sexual nas escolas brasileiras, o "sexo bem educado" certamente não pertence mais ao universo positivista e eugenista das primeiras décadas do século XX. O novo "sexo bem educado" passou agora a ocupar territórios vizinhos, como a ideia de "sexo responsável", "sexo saudável" e "sexo seguro". Assim, podemos dizer que uma "epistemologia" da saúde, da responsabilidade e do binômio risco/segurança vem produzindo uma educação sexual definida por uma ideia específica sobre o "bem viver". No cenário educacional contemporâneo, e tendo por objetivo específico delimitar parâmetros sobre a vida e a felicidade, a educação sexual seguiu rumos epistemológicos diversos, como a psicologia do desenvolvimento, a sociologia das representações sociais e a própria fisiologia da saúde.

Uma vez mais, na tentativa de esboçar contornos "epistemológicos", reporto-me à história e ao conceito de sexualidade, tal como definida por Michel Foucault, pois penso ser esse um horizonte importante para pensarmos sobre a sexualidade na educação. Desse ponto de vista, a presença da sexualidade na escola pode perfeitamente se traduzir na função de reproduzir o dispositivo de controle dos corpos, assim como em paradigma biopolítico de controle da vida, pois foi justamente na instituição escolar que se instauraram historicamente os dispositivos disciplinares e de governamento sobre os corpos de crianças e jovens ${ }^{4}$. Como afirma Helena Altman (2001) em sua análise dos PCNs, também amparada pelo referencial foucaultiano, estes documentos provocam uma

4 A ideia de governamento é oriunda do conceito foucaultiano de governamentalidade (VEIGA-NETO, 2002). 
incitação ao discurso sobre o sexo na escola, isto é, produzem uma verdadeira explosão discursiva: a proposta era que, no interior dos pressupostos dos temas transversais, "a orientação sexual deve impregnar toda a área educativa". Com Foucault, aprendemos que por meio da incitação ao discurso do sexo se instauram mecanismos de controle sobre os corpos dos indivíduos, exercidos não somente dentro de um sistema de punições e proibições, mas, especialmente, por meio de mecanismos que produzem sujeitos e seus corpos sexuados. Tal produção se dá no sentido do exercício do controle sobre a forma ideal de viver a sexualidade, isto é, de forma normativa, tendo em vista as práticas sexuais monogâmicas, heterossexuais e reprodutivas. As análises realizadas sobre os $P C N s$ demonstram que estes assumem uma abordagem preventiva e, neste contexto, prevenir as práticas sexuais de "risco" seria a tônica normativa na construção de uma forma ideal de sexualidade:

Ao trata do tema Orientação Sexual, busca-se considerar a sexualidade como algo inerente à vida e à saúde, que se expressa desde cedo no ser humano. Engloba o papel social do homem e da mulher, o respeito por si e pelo outro, as discriminações e os estereótipos atribuídos e vivenciados em seus relacionamentos, o avanço da AIDS e da gravidez indesejada na adolescência, entre outros, que são problemas atuais e preocupantes (BRASIL, 2000, p. 107).

No interior do fascículo de Orientação Sexual há um subitem denominado Relações de Gênero, com duas páginas e meia de texto. A inserção do tema se dá enquanto conteúdo específico da Orientação Sexual. Os objetivos para a abordagem são:

[...] combater relações autoritárias, questionar a rigidez dos padrões de conduta estabelecidos para homens e mulheres e apontar para a sua transformação. A flexibilização dos padrões visa permitir a expressão de potencialidades existentes em cada ser humano que são dificultadas pelos estereótipos de gênero. Como exemplo comum pode-se lembrar a repressão das expressões de sensibilidade, intuição e meiguice nos meninos ou de objetividade e agressividade nas meninas (BRASIL, 2000, p. 144).

Em um momento importante do texto ressalta-se que a "a abordagem das relações de gênero com as crianças dessa faixa etária, convém esclarecer, é 
uma tarefa delicada". Por que seriam abordagens sobre relações de gênero mais "delicadas" que as intervenções sobre a sexualidade? Nesse momento, é fundamental a tarefa de escutar o discurso produzido nesse documento. Em primeiro lugar, apesar do texto tratar das relações desiguais entre homens e mulheres na perspectiva histórica, aquilo que se compreende por gênero no texto são os tais "papéis sexuais" ou "papéis de gênero". O principal elemento presente nesse "conteúdo" específico de Orientação Sexual são as características ou "estereótipos" do masculino e do feminino, isto é, a "sensibilidade e a meiguice" de meninos e a "objetividade e a agressividade" das meninas. Além disso, o texto ressalta a importância de intervenção nos momentos de "discriminação de um aluno em seu grupo, com apelidos jocosos e às vezes questionamento sobre sua sexualidade. O professor deve então sinalizar a rigidez das regras existentes nesse grupo que definem o que é ser menino ou menina" (BRASIL, 2000, p. 145).

O caráter "delicado" do tema advém da norma social produzida no interior do dispositivo da sexualidade, isto é, a norma da heterossexualidade ou, como a denominou Judith Butler, a heteronormatividade. Em uma palavra, a dificuldade ou o caráter "delicado" apontado pelo texto dos $P C N s$ advém de uma confusão entre a ideia de gênero, definida não como categoria de análise das relações de poder entre os gêneros, como a pensou Joan Scott [...] mas sim, em virtude da percepção do gênero como "papéis" a serem desempenhados pelos dois "sexos biológicos" determinados. No âmbito daquela confusão conceitual, só há espaço para a correspondência entre corpo-sexo-desejo, isto é, corpo "masculinopênis-desejo feminino" e "feminino-vagina-desejo masculino" de modo que as características atribuídas aos dois gêneros, isto é, meiguice, objetividade e agressividade, constituem uma resposta imediata a esse sistema normativo de sexo-gênero. Nessa perspectiva, trabalhar as relações de gênero significa apenas e tão somente demonstrar que meninos podem ser também meigos e sensíveis sem que isso possa "ferir" sua masculinidade, e que meninas podem ser agressivas e objetivas, além de gostarem de futebol, sem que essas características firam sua feminilidade.

É importante ressaltar que, nessa perspectiva, alunos e alunas gays, lésbicas e transexuais permanecerão sem lugar no ambiente normativo da escola, como se pode observar na citação abaixo:

Eu já trabalhei com duas meninas que se diziam homo, mas elas faziam isso pra chamar atenção. Agora ver beijo na boca entre duas meninas, me choca. Não te choca? Esse liberalismo me choca um pouco. Ver duas meninas se beijando isso me choca. Isso eu não trabalhei bem em mim eu não consigo 
aceitar. E a mídia influencia muito, incentivando o homossexualismo. Nas novelas $[\ldots](\text { Ana })^{5}$.

Essa fala bastante significativa indica a dificuldade em relação a um possível questionamento do sistema heteronormativo na escola. Mesmo que algumas experiências educacionais já tenham definido que questões sobre a homossexualidade requerem uma abordagem específica a respeito da diversidade sexual, o esforço para minimamente colocar perguntas sobre a heteronormatividade permanece um grande desafio ainda não contemplado. Para o discurso escolar, em um primeiro momento, o importante é negar a existência de alunos e alunas homossexuais e bissexuais, pois a infância e a juventude são aclamadas como fases transitórias em relação ao exercício da sexualidade, de modo que, se bem conduzida por profissionais competentes, os jovens serão restituídos ao seu curso "normal". Se a presença de alunos e alunas homossexuais dentro da escola já é um incômodo, então, a partir daquela perspectiva, a experiência da transexualidade se torna verdadeiramente insuportável do ponto de vista da instituição escolar, pois, diante de seus corpos transformados, a fala competente da instituição não vê esperança de retorno à norma heterossexual. Assim, aquilo que resta é o afastamento desses corpos indesejáveis, isto é, a expulsão, que hoje se constitui em um elemento importante da evasão escolar ${ }^{6}$.

\section{Re-territorializando a sexualidade na escola}

É importante lembrarmos uma vez mais que qualquer decisão teórica e epistemológica é também política. Em se tratando da sexualidade, é também importante que se faça presente uma reflexão sobre as implicações das políticas de sexualidade. Lembremos que foi o dispositivo da sexualidade que instaurou o regime da heterossexualidade compulsória em todos os âmbitos da nossa vida. A heterossexualidade compulsória ou heteronormatividade é o conceito a partir do qual Judith Butler (1999) analisou as relações de poder entre homens e mulheres

5 Entrevista obtida no âmbito de pesquisa realiza pelo grupo de pesquisa sobre gênero e sexualidade nas escolas de Curitiba. O nome da professora é fictício.

6 Uma série de pesquisas realizadas e em andamento vem demonstrando que a experiência transexual é marcada pela expulsão da instituição escolar, com consequências sócias importantes na trajetória de vida desses indivíduos. 
e entre homossexualidade e heterossexualidade, demonstrando a construção do dispositivo da sexualidade como marcado pela norma heterossexual.

Se tomarmos como certo o lugar da sexualidade na instituição escolar, é importante que demarcar os temas que envolvem o trabalho na instituição escolar. Pesquisas realizadas com professoras/es e alunas/os vêm demonstrando a necessidade de uma formação específica tendo em vista a diversidade sexual presente no universo escolar. Alunas/os e professoras/es gays, lésbicas, bissexuais e transexuais compõem a diversidade contemporânea da instituição escolar; entretanto, para esta instituição que nasceu disciplinar e normatizadora, a diferença, ou tudo aquilo que está fora da norma, em especial, a norma sexual, mostra ser insuportável por transbordar os limites do conhecido. Assim, um trabalho que assuma como princípio a diversidade sexual marca a entrada em um "campo epistemológico" desconhecido, na medida em que a "epistemologia" reconhecível é a do sistema heteronormativo de correspondência entre sexo-gênero.

É decisivo o reencontro da sexualidade com as novas perspectivas dos estudos de gênero, recordando que os projetos de educação sexual dos anos 70 partiram de uma perspectiva libertária representada pelas abordagens feministas. Ao abordar o gênero como categoria de investigação, podemos recusar os lugares definidos para as dicotomias entre masculino e feminino, além de reconstruir os significados dos corpos, dos desejos e dos prazeres (SCOTT, 1995). Em outros termos, se assumirmos o gênero como categoria de análise das ciências humanas será possível formular novas epistemologias da sexualidade na escola. No mesmo sentido, mas radicalizando os questionamentos, isto é, problematizando a hegemonia linguística e cultural organizada a partir da heterossexualidade compulsória, a perspectiva dos estudos de gênero pode trazer à luz a heteronormatividade predominante nas práticas e discursos escolares. Sob tal perspectiva teórica, revela-se que o currículo possui uma matriz que, além de masculina, é heterossexual.

Essa nova perspectiva "epistemológica" se encontra com as teorizações queer ${ }^{7}$, produzindo questionamentos sobre os limites do discurso do sexo e da sexualidade marcados por uma concepção naturalizada, a-histórica e monolítica. Nesta ótica, o sexo está confinado à sua percepção biológica, responsável por delimitar a fronteira entre os sujeitos: masculino/feminino, heterossexual/ homossexual e normal/anormal. A teoria queer, partindo das indagações de

7 Queer em inglês significa estranho, esquisito, além de ser uma forma preconceituosa e violenta de abordar indivíduos homossexuais. Entretanto, no interior das universidades anglosaxãs, teóricas do gênero e da sexualidade se reapropriaram do vocábulo e produziram uma "epistemologia", ou um conjunto de articulações intelectuais, questionando o aprisionanento da concepção de corpo no sistema heteronormativo de sexo-gênero-desejo (SPARGO, 2007). 
Foucault e de Butler, representa um acervo importante de novas "perguntasrespostas", pois não é prescritiva, questionando principalmente as condições de possibilidade do conhecimento (SPARGO, 2007). Contra as abordagens da sexualidade marcadas pelo sistema heteronormativo de correspondência entre sexo-gênero, a teoria queer traz à tona a discussão não somente sobre a constituição dos sujeitos da sexualidade, como também sobre os próprios limites daquele modelo de construção de conhecimento e o quanto cada sujeito ou grupo suporta (des)conhecer. Neste sentido, a teoria queer demonstra que o sexo, o corpo e o próprio gênero são construções culturais, linguísticas e institucionais geradas no interior das relações de saber-poder-prazer, determinadas pelos limites do pensamento moderno. Assim, ao tratar da teoria queer, Guacira Lopes Louro (2004, p. 65) diz que: "[...] há limites para o conhecimento: nessa perspectiva, parece importante indagar o que ou quanto um dado grupo suporta conhecer". A teoria queer recusa a incorporação da alteridade no modelo hegemônico da norma sexual e social, argumentando que esta seria uma ação originária das "políticas de tolerância" que assumem a existência do binômio normal/anormal e, portanto, tendem a pacificar e normatizar, na medida do possível, a alteridade. Ao contrário disso, a teoria queer questiona as condições de possibilidade do conhecimento que produz a norma sexual e social.

Para finalizar. Primeiro, o trabalho com a diversidade sexual nas escolas pressupõe um conhecimento das disposições de professoras e professores que, por sua vez, deverão adentrar uma nova lógica do (des)conhecer, de sorte que tal trabalho não poderá jamais ser pautado pela pergunta formulada ao especialista sobre a normalidade das práticas e discursos sexuais. Perguntar pela normalidade é pertencer ao mundo definido e mapeado pelos processos disciplinadores e normalizadores. Segundo, para adentrar outra lógica, professores e professoras, segundo Deborah Britzman (1999), necessitam produzir a capacidade de desestabilizar o conhecimento em nome da liberdade. Nesta perspectiva, sexualidade, educação sexual e diversidade sexual se referem a práticas de liberdade, na medida em que os limites de nosso pensamento deverão ser transcendidos em nome de outras possibilidades tanto de conhecer como de amar. 


\section{REFERÊNCIAS}

ALTMAN, Helena. “Orientação sexual nos Parâmetros Curriculares Nacionais”. Revista de Estudos Feministas, a. 9, 2. Semestre 2001.

BARROSO, Carmem. "Pesquisa sobre educação sexual e democracia", Cadernos de Pesquisa, São Paulo, n.15, 1980.

. Educação Sexual. Debate Aberto. Petrópolis: Vozes, 1982.

BRASIL. Secretaria de Educação Fundamental. Parâmetros Curriculares Nacionais: pluralidade cultural e orientação sexual / Secretaria de Educação Fundamental. 2. ed. Rio de Janeiro: DP\&A, 2000.

BRITZMAN, Deborah. Curiosidade, sexualidade e currículo. In: LOURO, G. L. (Org.). O corpo educado. Pedagogias da Sexualidade. Belo Horizonte: Autêntica, 1999.

BRUSQUINI, Carmem; BARROSO, Cristina. Caminhando juntas: uma experiência em educação sexual na periferia de São Paulo. Cadernos de Pesquisa, São Paulo, n. $45,1983$.

BUTLER, Judith. Corpos que pesam. In: LOURO, Guacira Lopes (Org.). O corpo educado. Pedagogias da Sexualidade. Belo Horizonte: Autêntica, 1999.

CÉSAR, Maria Rita de Assis. Da escola disciplinar à pedagogia do controle. Tese (Doutorado) - Faculdade de Educação, Unicamp, 2004.

$\overline{\text { Unesp, } 2008 .}$

. A invenção da adolescência no discurso psicopedagógico. São Paulo: Editora

COSTA, Jurandir Freire. Ordem Médica e Norma Familiar. Rio de Janeiro: Graal, 1983.

FOUCAULT, Michel. História da Sexualidade I: a vontade de saber. Rio de Janeiro: Graal, 1984.

LOURO, Guacira Lopes. Um corpo estranho. Ensaios sobre sexualidade e teoria queer. Belo Horizonte: Autêntica, 2004.

MARQUES, Vera Beltrão. A Medicalização da Raça. Médicos, educadores e discurso eugênico. Campinas: Ed. Unicamp, 1994.

SCOTT, Joan Gênero: uma categoria útil de análise histórica. Educação e Realidade, Porto Alegre, v. 20, n. 2, jul./dez. 1995. 
SILVA, Tomas Tadeu. Documentos de Identidade. Uma introdução às teorias do currículo. Belo Horizonte: Autêntica, 1999.

SPARGO, Tamisin. Foucault y la teoria queer. Barcelona: Gedisa, 2007.

VEIGA-NETO, Alfredo. Coisas de Governo. In: RAGO, Margareth; ORLANDI, Luis B. Lacerda; VEIGA-NETO, Alfredo. Imagens de Foucault e Deleuze. Ressonâncias nietzschianas. Rio de Janeiro: DP\&A, 2002.

VIDAL, Diana Gonçalves. "Educação sexual: produção de identidades de gênero na década de 1930". In: SOUZA, Cinthia Pereira (Org.). História da Educação. Processos, práticas e saberes. São Paulo: Escrituras, 2002.

WEREBE, Maria José Garcia. Sexualidade, Política e Educação. Campinas: Editora Autores Associados, 1998.

Texto recebido em 9 de junho de 2009. Texto aprovado em de 10 julho de 2009. 